\title{
Predictive factors of death in neonates with hypoxic-ischemic encephalopathy receiving selective head cooling
}

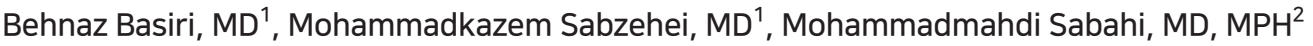 \\ ${ }^{1}$ Department of Pediatrics, Hamadan University of Medical Sciences, Hamadan, Iran; ${ }^{2}$ Neurosurgery Research Group (NRG), Student Research Committee, Hamadan \\ University of Medical Sciences, Hamadan, Iran
}

\begin{abstract}
Background: Severe perinatal asphyxia results in multiple organ involvement, neonate hospitalization, and eventual death. Purpose: This study aimed to investigate the predictive factors of death in newborns with hypoxic-ischemic encephalopathy (HIE) receiving selective head cooling.

Methods: This cross-sectional descriptive-retrospective study was conducted from 2013 to 2018 in Fatemieh Hospital of Hamadan and included 51 newborns who were admitted to the neonatal intensive care unit with a diagnosis of HIE. Selective head cooling for patients with moderate to severe HIE began within 6 hours of birth and continued for 72 hours. The required data for the predictive factors of death were extracted from the patients' medical files, recorded on a premade form, and analyzed using SPSS ver. 16 .

Results: Of the 51 neonates with moderate to severe HIE who were treated with selective head cooling, 16 (31\%) died. There were significant relationships between death and the need for advanced neonatal resuscitation $(P=0.002)$, need for mechanical ventilation $(P=0.016), 1$-minute Apgar score $(P=0.040)$, and severely abnormal amplitude-integrated electroencephalography (a-EEG) $(P=0.047)$. Multiple regression of variables or data showed that the need for advanced neonatal resuscitation was an independent predictive factor of death $(P=0.0075)$ and severely abnormal a-EEG was an independent predictive factor of asphyxia severity $(P=0.0001)$.

Conclusion: All cases of neonatal death in our study were severe HIE (stage 3). Advanced neonatal resuscitation was an independent predictor of death, while a severely abnormal a-EEG was an independent predictor of asphyxia severity in infants with HIE.
\end{abstract}

Key words: Death, Hypothermia, Brain hypoxia-ischemia, Newborn infant, Prognosis

\section{Key message}

Question: What is the most important factor that increases mortality in infants with hypoxic-ischemic encephalopathy
(HIE) who receive selective head cooling?

Finding: All cases of neonatal mortality were severe HIE (stage 3), and a severely abnormal amplitude-integrated electroencephalography and mortality were increased with the need for advanced neonatal resuscitation upon delivery.

Meaning: Advanced neonatal resuscitation affects HIE outcomes, and medical personnel should be prepared to provide the best intervention.

\section{Introduction}

The prevalence of perinatal asphyxia in developed countries is 2 per 1,000 births, whereas it is 10 times higher in developing countries. ${ }^{1)}$ The prevalence of neonatal encephalopathy is 3 per 1,000 births, whereas that of hypoxic-ischemic encephalopathy (HIE) is 1.5 per 1,000 births. ${ }^{2}$ It is well known that infants with moderate to severe HIE are at risk for adverse events, such as cerebral palsy, neurodevelopmental disorders, or death even after hypothermia. There is evidence from a large randomized controlled trial that included hypothermia is beneficial for neonates with HIE. Cooling reduces mortality without increasing major disability in survivors. ${ }^{3,4)}$ Therapeutic hypothermia is the standard treatment for infants with moderate to severe HIE. ${ }^{5)}$ Two methods are being evaluated in newborn infants with HIE: whole-body cooling and selective head cooling with mild systemic hypothermia.

In terms of prognosis, a mild form of asphyxia occurs without any neurological complications or with mild neurodevelopmental complications within 3 days. However, moderate and severe forms of asphyxia cause permanent neurological deficits and neurodevelopmental disorders. ${ }^{6}$ Magnetic resonance imaging (MRI) such as diffusion tensor image can be used as a suitable standard for the determination of damage severity. ${ }^{7}$ However, abnormal amplitude-integrated electroencephalogram (a-EEG) for 48 hours along with early abnormal MRI is a strong predictor of poor neurodevelopment. ${ }^{8)}$ Except for clinical manifestations, the use of a-EEG can be help predict brain damage of neonates

\footnotetext{
Corresponding author: Mohammadmahdi Sabahi, MD, MPH. Neurosurgery Research Group (NRG), Student Research Committee, Hamadan University of Medical Sciences, Hamadan, Iran 


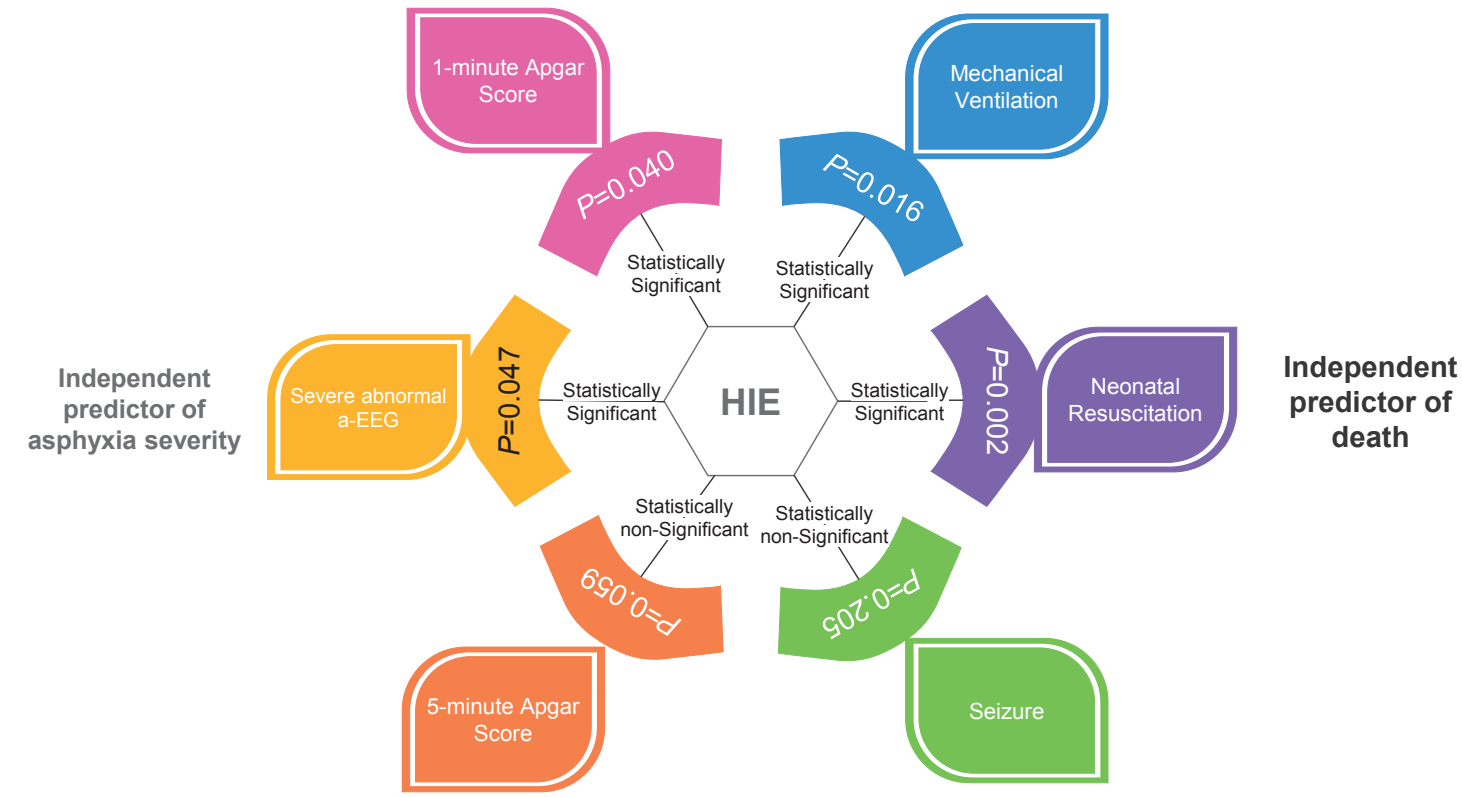

Graphical abstract

following asphyxia.9)

To date, various studies have used neonatal status at birth, the severity of HIE, EEG, biomarkers, and brain MRI to predict outcome in infants with HIE. ${ }^{10-13)}$ The primary outcome of this study was to investigate the predictive factors of death in infants with HIE after selective therapeutic head cooling.

\section{Methods}

This cross-sectional descriptive-retrospective study was carried out from April 2013 to September 2018 in the Fatemieh Hospital affiliated with the Hamadan University of Medical Sciences, Iran. The study was approved by the Ethics Committee of Hamadan University of Medical Sciences with the code IR. UMSHA.1395.391. Written informed consent was obtained from the parent of the patient who participated in this study. Fifty-one newborns admitted to the NICU with a diagnosis of HIE, confirmed by a neonatologist, and treated with selective head cooling were enrolled in the study.

Inclusion criteria were infants with $\geq 36$ weeks of gestational age (GA), who meet $\geq 1$ of criteria A, B, and C, as described below ${ }^{14)}$ :

Criteria A

(1) Apgar score $<5$ at 10 minutes of age

(2) The continued need for ventilation 10 minutes after birth

(3) $\mathrm{pH}<7.0$ or base deficit $<-16$ in blood gases within 1 hour of birth

Criteria B

Moderate to severe encephalopathy, consisting of altered state of consciousness (as shown by lethargy, stupor, or coma) and $>1$ of the following:

(1) Hypotonia

(2) Abnormal reflexes, including oculomotor or papillary abnormalities

(3) The absent or weak sucking reflex

(4) Clinical seizures

Criteria C

a-EEG records (30 minutes)

(1) Moderately abnormal a-EEG background activity

(2) Severely abnormal a-EEG background activity

(3) Seizure activity

Exclusion criteria were infants with mild HIE, over 6 hours of age at the time of admission, major congenital anomalies, head trauma causing intracranial hemorrhage, severe intrauterine growth retardation with birth weight less than $1,800 \mathrm{~g}$, imperforated anus and coagulopathy with active bleeding.

HIE in the newborns was classified into 3 categories of mild, moderate, and severe based on the Sarnat staging system. ${ }^{15,16)}$ Data needed for the study, including mother's age, newborn's gender and weight, GA, delivery method, seizure, neonatal resuscitation, 1- and 5-minute Apgar scores, blood gas analysis, analysis of creatine phosphokinase (CPK) and lactate dehydrogenase (LDH) enzymes, brain imaging results, a-EEG, need for ventilator and infant outcome (death or recovery) were extracted from the patients' medical records and recorded in a premade questionnaire.

Cool-cap (Olympic Medical Cool Care System, Olympic Medical, Seattle, WA, USA) for patients with moderate to severe HIE should begin within 6 hours of birth and continue for 72 
hours.

The system consists of a cooling unit and a pump that circulate water through the cap. The initial water temperature is set between $8^{\circ} \mathrm{C}$ and $12^{\circ} \mathrm{C}$. All infants were placed under a radiant warmer, the temperature-controlled by an abdominal skin probe, and the rectal temperature was maintained at $34^{\circ} \mathrm{C}-35^{\circ} \mathrm{C}$. At the beginning of hypothermia, the radiant warmer was switched off for 20 to 30 minutes, then restarted when the rectal temperature was reduced to $35.5^{\circ} \mathrm{C}$. Slow rewarming to normal temperature was performed at the end of the 72 hours cooling period that lasts 4 hours. ${ }^{3)}$

a-EEG was used for 20 minutes to aid in the diagnosis of moderate to severe encephalopathy. ${ }^{11,17)}$ We classified infants if they had a background a-EEG voltage that was normal (upper margin $>10 \mu \mathrm{V}$ and lower margin $>5 \mu \mathrm{V}$ ), moderately abnormal (upper margin $>10 \mu \mathrm{V}$ and lower margin $<5 \mu \mathrm{V}$ ), or severely abnormal (upper margin $<10 \mu \mathrm{V}$ and lower margin $<5 \mu \mathrm{V}$ ), seizures identified by a sudden increase in voltage accompanied by narrowing of the margin of a-EEG activity followed by a brief period of suppression, or both. ${ }^{18)}$ Clinical and/or a-EEGdetected seizures were treated according to standard neonatal seizure protocol. Brain imaging (cranial ultrasound and MRI) was performed. Advanced neonatal resuscitation was defined as basic resuscitation plus endotracheal intubation, chest compression, and administration of epinephrine/volume as needed.

The data were analyzed using SPSS ver. 16.0 (SPSS Inc., Chicago, IL., USA). In the inferential statistics section, the KolmogorovSmirnov test was used to examine the normal distribution of quantitative variables and the variables were compared using the chi-square test, the $t$ test, and Mann-Whitney $U$ test.

\section{Results}

Fifty-one infants with asphyxia were treated with therapeutic hypothermia using the selective head cooling. The mean GA and birth weight were $38.3 \pm 1.6$ weeks and 3,132 $\pm 477 \mathrm{~g}$. Seizure, mechanical ventilation, and severely abnormal a-EEG were observed in 22, 31, and 20 neonates, respectively. Sixteen infants (31\%) died. The general characteristics of the studied neonates are presented in Table 1. Comparison of the survive and nonsurvive infants in terms of predictor factors associated with the death of the infants with asphyxia who received cool-cap therapy indicated that there were significant relationships between death and advanced neonatal resuscitation $(P=0.002)$, mechanical ventilation $(P=0.016), 1$-minute Apgar score $(P=0.040)$, and severely abnormal a-EEG $(P=0.047)$ (Table 2$)$. Multiple regression was performed simultaneously which indicated that only neonatal resuscitation was an independent factor associated with infant death $(P=0.0075)$. The results of the odds ratio showed that the chances of dying among resuscitated newborns were 23.55 times higher than those among infants who were not resuscitated (Table 3).

In terms of staging damage severity, 26 of the 51 neonates
(51\%) who received selective head cooling treatment were in stage 2 and 25 (49\%) in stage 3. The general characteristics of the newborns are given in Table 4. According to the results, there were significant relationships between the need for mechanical ventilation $(P=0.008)$ and severely abnormal a-EEG $(P=0.0001)$ and asphyxia severity (Table 5). In univariate analysis, parameters related to the asphyxia severity were considered independent, and simultaneous multiple regression was performed which indicated that only severely abnormal EEG was related to asphyxia severity $(P=0.0001)$. The results of the odds ratio showed that the chance of stage 3 to stage 2 in neonates with severely abnormal a-EEG was 63 times higher than in neonates with normal

Table 1. General characteristics of the neonates with asphyxia treated with topical hypothermia

\begin{tabular}{|c|c|c|c|}
\hline \multirow{2}{*}{ Variable } & \multicolumn{2}{|c|}{ Outcome } & \multirow{2}{*}{$\begin{array}{l}\text { Total } \\
(n=51)\end{array}$} \\
\hline & Expire $(n=16)$ & Survive $(n=35)$ & \\
\hline Maternal age (yr) & $29.1 \pm 5.3$ & $28.2 \pm 6.5$ & $28.5 \pm 6.12$ \\
\hline \multicolumn{4}{|l|}{ Sex } \\
\hline Male & $7(23.33)$ & $23(76.67)$ & $30(100)$ \\
\hline Female & $9(42.86)$ & $12(57.14)$ & $21(100)$ \\
\hline Birth weight (g) & $3,149(406)$ & $3,124(512)$ & $3,132(477)$ \\
\hline GA & $38.5(1.6)$ & $38.2(1.5)$ & $38.33(1.6)$ \\
\hline \multicolumn{4}{|l|}{ Delivery method } \\
\hline Vaginal & $7(30.43)$ & $16(69.57)$ & $23(100)$ \\
\hline Cesarean & $9(32.14)$ & $19(67.86)$ & $28(100)$ \\
\hline \multicolumn{4}{|l|}{ Seizure } \\
\hline Yes & $9(40.91)$ & $13(59.09)$ & $22(100)$ \\
\hline No & $7(24.14)$ & $22(75.86)$ & $29(100)$ \\
\hline \multicolumn{4}{|c|}{ Advanced neonatal resuscitation } \\
\hline Yes & $15(55.56)$ & $12(44.44)$ & $27(100)$ \\
\hline No & $1(4.17)$ & $23(95.83)$ & $24(100)$ \\
\hline \multicolumn{4}{|l|}{ Apgar score } \\
\hline 1 Minute & $1.63 \pm 1.5$ & $2.69 \pm 1.59$ & $2.35 \pm 1.62$ \\
\hline 5 Minutes & $3.69 \pm 2.02$ & $4.83 \pm 1.84$ & $4.47 \pm 1.95$ \\
\hline $\mathrm{pH}$ & $7.22 \pm 0.13$ & $7.3 \pm 0.13$ & $7.27 \pm 0.13$ \\
\hline $\mathrm{BE}$ & $-4.8 \pm 13.6$ & $-3.5 \pm 10.6$ & $-3.9 \pm 11.5$ \\
\hline $\mathrm{HCO}_{3}$ & $15.3 \pm 8$ & $15.8 \pm 6.4$ & $15.7 \pm 6.8$ \\
\hline \multicolumn{4}{|l|}{ Mechanical ventilation } \\
\hline Yes & $14(45.16)$ & $17(54.84)$ & $31(100)$ \\
\hline No & $2(10)$ & $18(90)$ & $20(100)$ \\
\hline CPK & $2,015 \pm 2,404$ & $2,055 \pm 1,777$ & $2,043 \pm 1,970$ \\
\hline LDH & $1,885 \pm 910$ & $1,956 \pm 743$ & $1,728 \pm 797$ \\
\hline \multicolumn{4}{|l|}{ a-EEG } \\
\hline Normal & $2(12.5)$ & $14(87.5)$ & $16(100)$ \\
\hline Moderate abnormal & $1(16.67)$ & 5 (83.33) & $6(100)$ \\
\hline Severe abnormal & $4(44.44)$ & $5(55.56)$ & $9(100)$ \\
\hline $\begin{array}{l}\text { Severe abnormal with } \\
\text { seizure }\end{array}$ & $9(45)$ & $11(55)$ & $20(100)$ \\
\hline \multicolumn{4}{|l|}{ Sarnat staging system } \\
\hline Stage 2 & $0(0)$ & $26(100)$ & $26(100)$ \\
\hline Stage 3 & $16(64)$ & $9(36)$ & $25(100)$ \\
\hline
\end{tabular}

Values are presented as mean \pm standard deviation or number (\%). $\mathrm{GA}$, gestational age; $\mathrm{pH}$, power of hydrogen; $\mathrm{BE}$, base excess; $\mathrm{HCO}_{3}$, bicarbonate; CPK, creatine phosphokinase; LDH, lactate dehydrogenase; a-EEG, amplitude-integrated electroencephalography. 
Table 2. Comparison of clinical characteristics of the live and dead newborns

\begin{tabular}{|c|c|c|c|c|c|}
\hline Parameter & B & SE & OR & $95 \% \mathrm{Cl}$ & $P$ value \\
\hline Maternal age (yr) & 0.024 & 0.05 & 1.025 & $0.929-1.131$ & 0.625 \\
\hline Female sex & 0.901 & 0.617 & 2.464 & $0.735-8.259$ & 0.144 \\
\hline GA & 0.139 & 0.196 & 1.147 & $0.781-1.685$ & 0.486 \\
\hline Delivery method (vaginal) & -0.079 & 0.607 & 0.923 & $0.281-3.038$ & 0.895 \\
\hline Seizure & -0.777 & 0.613 & 0.459 & $0.138-1.529$ & 0.205 \\
\hline Advanced neonatal resuscitation & 3.359 & 1.092 & 28.75 & $3.378-244.659$ & 0.002 \\
\hline $\mathrm{pH}$ & -4.321 & 2.312 & 0.013 & $0.0001-1.235$ & 0.062 \\
\hline $\mathrm{BE}$ & -0.001 & 0.027 & 0.99 & 0.939-1.043 & 0.714 \\
\hline $\mathrm{HCO}_{3}$ & -0.012 & 0.045 & 0.988 & $0.905-1.078$ & 0.782 \\
\hline Mechanical ventilation & 2.003 & 0.828 & 7.412 & $1.462-37.57$ & 0.016 \\
\hline \multicolumn{6}{|l|}{ Apgar score } \\
\hline 1 Minute & -0.58 & 0.282 & 0.559 & $0.322-0.974$ & 0.040 \\
\hline 5 Minutes & -0.34 & 0.181 & 0.711 & $0.499-1.013$ & 0.059 \\
\hline CPK & -0.00001 & 0.0002 & 1 & 0.999-1.001 & 0.946 \\
\hline LDH & 0.0004 & 0.0004 & 1.0004 & 0.999-1.001 & 0.305 \\
\hline \multicolumn{6}{|l|}{ a-EEG } \\
\hline Moderate & 0.336 & 1.331 & 1.4 & $0.103-19.01$ & 0.8 \\
\hline Moderate to severe & 1.723 & 1.011 & 5.6 & $0.773-40.595$ & 0.088 \\
\hline Severe abnormal & 1.745 & 0.879 & 5.727 & $1.022-32.104$ & 0.047 \\
\hline Sarnat staging system & 20.312 & $2,296.8$ & - & - & 0.993 \\
\hline
\end{tabular}

B, probability of a type II error or power of test (estimate); $\mathrm{SE}$, standard error; OR, odds ratio; $\mathrm{Cl}$, confidence interval; $\mathrm{GA}$, gestational age; $\mathrm{pH}$, power of hydrogen; $\mathrm{BE}$, base excess; $\mathrm{HCO}_{3}$, bicarbonate; $\mathrm{CPK}$, creatine phosphokinase; $\mathrm{LDH}$, lactate dehydrogenase; a-EEG, amplitude-integrated electroencephalography.

Boldface indicates a statistically significant difference with $P<0.05$.

Table 3. Multivariate regression analysis

\begin{tabular}{lccclc}
\hline Parameter & B & SE & OR & $95 \% \mathrm{Cl}$ & \multicolumn{1}{c}{$P$ value } \\
\hline Advanced neonatal resuscitation & 3.159 & 1.181 & 23.55 & $2.325-238.600$ & 0.0075 \\
Mechanical ventilation & 1.259 & 1.091 & 3.522 & $0.415-29.900$ & 0.249 \\
Apgar score, 1 minute & -0.364 & 0.316 & 0.695 & $0.374-1.292$ & 0.25 \\
a-EEG & & & & & \\
Moderate & -0.011 & 1.559 & 0.989 & $0.047-21.000$ & 0.994 \\
Moderate to severe & 0.702 & 1.293 & 2.018 & $0.160-25.429$ & 0.5871 \\
Severe abnormal & 1.702 & 1.126 & 5.486 & $0.604-49.849$ & 0.131
\end{tabular}

$\mathrm{B}$, probability of a type II error or power of test (estimate); SE, standard error; OR, odds ratio; Cl, confidence interval; a-EEG, amplitude-integrated electroencephalography.

Boldface indicates a statistically significant difference with $P<0.05$.

a-EEG, and severely abnormal a-EEG was an independent predictor of asphyxia severity (Table 6).

\section{Discussion}

In this study, the comparison of surviving and nonsurviving newborns showed that neonatal advanced resuscitation, need for mechanical ventilation, lower 1-minute Apgar score, and severe abnormalities in a-EEG increased the risk of mortality in newborns with HIE.

Fifty-one neonates with moderate to severe HIE treated with selective head cooling in the present study and 16 infants (31.3\%) died. Shankaran et al. ${ }^{19)}$ demonstrated $24 \%$ in the hypothermia group and $37 \%$ in the control group died. According to studies by Srinivasakumar et al. ${ }^{20)}$ and Gluckman et al., ${ }^{11)}$ hypothermia appears to be less protective in infants with the most severe HIE. All cases of neonatal death in our study were severe HIE (stage 3). Thus, one of the reasons for the high mortality rate in our study compared to the study of Shankaran et al. ${ }^{19)}$ was the high rate of patients with severe $\mathrm{HIE}, 49 \%$ versus $32 \%$ respectively. ${ }^{19)}$ As a result, head cooling reduces neonatal death compared to routine care.

Regarding the effect of the lower Apgar score at birth, other studies showed that acidemia and lower Apgar scores were associated with a worse outcome of HIE infants. ${ }^{21,22)}$ This is while indications for hypothermia therapy include a-EEG, Apgar score, the neurologic score for encephalopathy, $\mathrm{pH}$, and lactate levels. ${ }^{23)}$ In another study, metabolic acidosis was observed only in infants with grade $3 \mathrm{HIE} .{ }^{24)}$ In our study, the mean $\mathrm{pH}$ in HIE 
Table 4. Characteristics of the newborns by damage severity

\begin{tabular}{|c|c|c|c|}
\hline \multirow{2}{*}{ Variable } & \multicolumn{2}{|c|}{ Sarnat staging } & \multirow{2}{*}{$\begin{array}{c}\text { Total } \\
(n=51)\end{array}$} \\
\hline & Stage $2(n=26)$ & Stage $3(n=25)$ & \\
\hline Maternal age (yr) & $28 \pm 6.3$ & $29.0 \pm 6.0$ & $28.5 \pm 6.1$ \\
\hline \multicolumn{4}{|l|}{ Sex } \\
\hline Male & $16(53.33)$ & $14(46.67)$ & $30(100)$ \\
\hline Female & $10(47.62)$ & $11(52.38)$ & $21(100)$ \\
\hline Birth weight (g) & $3,036 \pm 459$ & $3,231 \pm 486$ & $3,132 \pm 477$ \\
\hline GA & $38.0 \pm 1.6$ & $38.6 \pm 1.5$ & $38.3 \pm 1.6$ \\
\hline \multicolumn{4}{|l|}{ Delivery method } \\
\hline Vaginal & $14(60.87)$ & $9(39.13)$ & $23(100)$ \\
\hline Cesarean & $12(42.86)$ & $16(57.14)$ & $28(100)$ \\
\hline \multicolumn{4}{|l|}{ Seizure } \\
\hline Yes & $12(54.55)$ & $10(45.45)$ & $22(100)$ \\
\hline No & $14(48.28)$ & $15(51.72)$ & $29(100)$ \\
\hline \multicolumn{4}{|c|}{ Advanced neonatal resuscitation } \\
\hline Yes & $11(40.74)$ & $16(59.26)$ & $27(100)$ \\
\hline No & $15(62.50)$ & $9(37.50)$ & $24(100)$ \\
\hline $\mathrm{pH}$ & $7.3 \pm 0.14$ & $7.25 \pm 0.13$ & $7.27 \pm 0.14$ \\
\hline $\mathrm{BE}$ & $-4.2 \pm 11.27$ & $-3.7 \pm 12.0$ & $-3.9 \pm 11.5$ \\
\hline $\mathrm{HCO}_{3}$ & $15.5 \pm 6.3$ & $15.8 \pm 7.5$ & $15.7 \pm 6.8$ \\
\hline \multicolumn{4}{|l|}{ Mechanical ventilation } \\
\hline Yes & $11(35.48)$ & $20(64.52)$ & $31(100)$ \\
\hline No & $15(75.00)$ & $5(25.00)$ & $20(100)$ \\
\hline \multicolumn{4}{|l|}{ Apgar score } \\
\hline 1 Minute & $2.42 \pm 1.27$ & $2.28 \pm 1.95$ & $2.35 \pm 1.62$ \\
\hline 5 Minutes & $4.9 \pm 1.6$ & $3.9 \pm 2.1$ & $4.4 \pm 1.9$ \\
\hline CPK & $2,163 \pm 1,951$ & $1,917 \pm 2,022$ & $2,043 \pm 1,970$ \\
\hline $\mathrm{LDH}$ & $1,644 \pm 728$ & $1,825 \pm 850$ & $1,732 \pm 787$ \\
\hline \multicolumn{4}{|l|}{ Outcome } \\
\hline Expire & $0(0)$ & $16(100)$ & $16(100)$ \\
\hline Survive & $26(74.29)$ & $9(25.71)$ & 35 (100) \\
\hline \multicolumn{4}{|l|}{ EEG } \\
\hline Normal & $14(87.5)$ & $2(12.5)$ & $16(100)$ \\
\hline Moderate abnormal & $5(83.33)$ & $1(16.67)$ & $6(100)$ \\
\hline $\begin{array}{l}\text { Moderate to severe } \\
\text { abnormal }\end{array}$ & $5(55.56)$ & $4(44.44)$ & $9(100)$ \\
\hline Severe abnormal & $2(10)$ & $18(90)$ & 20 (100) \\
\hline
\end{tabular}

Values are presented as mean \pm standard deviation or number (\%).

$\mathrm{GA}$, gestational age; $\mathrm{pH}$, power of hydrogen; $\mathrm{BE}$, base excess; $\mathrm{HCO}_{3}$, bicarbonate; CPK, creatine phosphokinase; LDH, lactate dehydrogenase; EEG, amplitude-integrated electroencephalography.

infants was 7.3 in grade 2 and 7.25 in grade 3 , indicating that the level of acidosis was higher in infants with grade $3 \mathrm{HIE}$.

In our study, the mean values of arterial $\mathrm{PH}$ were higher than in other studies and there was no significant difference between mean value of arterial $\mathrm{PH}$ and infant death and staging of HIE. These differences may be due to different time of sampling. In our study, umbilical cord arterial blood gas analysis at birth was not performed and atrial blood gas sampling was taken at least half an hour later after birth and after initial stabilization of neonates. Umbilical cord arterial blood gas analysis is a simple, accurate, and reliable tool for diagnosing asphyxia because of HIE is hypoxic events and metabolic acidosis. Therefore, the results of umbilical cord arterial blood gas analysis at birth are a gold standard that reflects blood gas and basal acid status immediately before birth. ${ }^{25)}$ Among the parameters of arterial blood gas, umbilical cord $\mathrm{pH}$ is the most important factor and the severity of acidosis is related to the severity of the injury ${ }^{26)}$ but in another study, it was noted that umbilical cord gas alone has its limitations and cannot be used as the sole indicator for the diagnosis of HIE. For this reason, the combination of umbilical artery $\mathrm{pH}$ and Apgar score to overcome these limitations was used. ${ }^{27,28)}$ Williams' study showed that there was no correlation between $\mathrm{pH}$ and neonatal death in infants with hypoxic-ischemic encephalopathy that These findings same with ours and differ from those of majority of researchers. ${ }^{29)}$

The results of the multiple regression analysis of the study data showed that only the advanced neonatal resuscitation (including endotracheal intubation, chest compression, and epinephrine/ volume administration) was an independent factor associated with the death of the newborns. The results of the odds ratio showed that the chances for the neonatal death were 23.55 times higher than those of the infants who were not resuscitated. Another study indicated that 107 of the 4,629 newborns (or 2.3\%) needed neonatal resuscitation, and the need for advanced neonatal resuscitation was significantly related to death in newborns with asphyxia. ${ }^{30)}$ It was demonstrated in another study that after implementation of the neonatal resuscitation program (NRP), the number of newborns with asphyxia who were not resuscitated and the length of stay decreased significantly, while the 1-minute Apgar score increased. ${ }^{31)}$ Regarding this increase in the Apgar score and advantages and disadvantages of resuscitation in neonates with asphyxia, it should be noted that resuscitation conditions including 100\% oxygenation for the resuscitation of asphyxia infants ${ }^{32)}$ and appropriate training of resuscitators in developing countries on the correct implementation of the NRP can improve the possible complications. ${ }^{33)} \mathrm{A}$ study on 60 neonates with HIE (including 39 infants with moderate to severe HIE) showed that neonatal clinical markers, including Apgar score and neonatal resuscitation, were better predictors for HIE than biochemical markers such as placental artery $\mathrm{pH}$, base excess, and lactate level. Consistent with our study, neonatal resuscitation (93\% sensitivity, $99 \%$ specificity) was the most effective predictor for infants with moderate to severe HIE. ${ }^{34)}$

In the present study, despite the high CPK and LDH levels, the severity of damage and death in HIE infants had no statistically significant relationships with these 2 enzymes. Beken et al. ${ }^{35}$ ) found that serum creatine kinase BB was much higher in infants who died due to severe HIE and that biomarker changes occurred before the clinical presentation. In addition, although $\mathrm{LDH}$ and lactate levels increase significantly during HIE progression, they have no high predictive value in advanced HIE (stages 2 and 3). Since the neonates in the present study were at stages 2 and 3 , no significant relationship was found between their mortality and high levels of LDH and lactate, which indicated the conformity of these studies. In addition, LDH levels were higher in the saliva of HIE infants than in that of the control group. ${ }^{36}$ Finally, it can be said that none of these metabolic and biochemical markers are 
Table 5. Effective factors associated with the damage severity of neonates with asphyxia

\begin{tabular}{|c|c|c|c|c|c|}
\hline Parameter & B & SE & $\mathrm{OR}$ & $95 \% \mathrm{Cl}$ & $P$ value \\
\hline Maternal age & 0.028 & 0.047 & 1.029 & $0.939-1.147$ & 0.541 \\
\hline Female sex & 0.229 & 0.570 & 1.257 & $0.411-3.842$ & 0.688 \\
\hline GA & 0.214 & 0.183 & 1.239 & $0.866-1.773$ & 0.242 \\
\hline Delivery method (vaginal) & -0.730 & 0.573 & 0.482 & $0.157-1.482$ & 0.203 \\
\hline Seizure & 0.251 & 0.567 & 1.286 & $0.423-3.906$ & 0.658 \\
\hline Advanced neonatal resuscitation & 0.886 & 0.575 & 2.424 & $0.785-7.489$ & 0.124 \\
\hline $\mathrm{pH}$ & -2.809 & 2.151 & 0.06 & $0.001-4.084$ & 0.192 \\
\hline $\mathrm{BE}$ & 0.003 & 0.024 & 1.003 & $0.956-1.053$ & 0.891 \\
\hline $\mathrm{HCO}_{3}$ & 0.007 & 0.041 & 1.007 & 0.929-1.092 & 0.869 \\
\hline Mechanical ventilation & 1.696 & 0.638 & 5.455 & $1.561-19.063$ & 0.008 \\
\hline \multicolumn{6}{|l|}{ Apgar score } \\
\hline 1 Minute & -0.056 & 0.175 & 0.946 & $0.671-1.334$ & 0.751 \\
\hline 5 Minutes & -0.285 & 0.159 & 0.752 & $0.55-1.027$ & 0.073 \\
\hline CPK & -0.00007 & 0.0001 & 0.9999 & 0.999-1.0002 & 0.654 \\
\hline LDH & 0.0003 & 0.0004 & 1.0003 & 0.999-1.001 & 0.412 \\
\hline \multicolumn{6}{|l|}{ a-EEG } \\
\hline Moderate & 0.336 & 1.331 & 1.4 & $0.103-19.013$ & 0.8 \\
\hline Moderate to severe & 1.723 & 1.011 & 5.6 & $0.773-40.595$ & 0.088 \\
\hline Severe abnormal & 4.143 & 1.062 & 63.0 & $7.865-504.648$ & 0.0001 \\
\hline Outcome (expire) & 20.374 & $2,369.185$ & - & - & 0.993 \\
\hline
\end{tabular}

$\mathrm{B}$, probability of a type II error or power of test (estimate); $\mathrm{SE}$, standard error; $\mathrm{OR}$, odds ratio; $\mathrm{Cl}$, confidence interval; $\mathrm{GA}$, gestational age; $\mathrm{pH}$, power of hydrogen; $\mathrm{BE}$, base excess; $\mathrm{HCO}_{3}$, bicarbonate; $\mathrm{CPK}$, creatine phosphokinase; $\mathrm{LDH}$, lactate dehydrogenase; a-EEG, amplitude-integrated electroencephalography. Boldface indicates a statistically significant difference with $P<0.05$.

Table 6. Multivariate regression analysis

\begin{tabular}{lccccl}
\hline Parameter & $\mathrm{B}$ & $\mathrm{SE}$ & $\mathrm{OR}$ & $95 \% \mathrm{Cl}$ & $P$ value \\
\hline Mechanical ventilation & 1.536 & 0.954 & 4.644 & $0.716-30.099$ & 0.107 \\
a-EEG & & & & & \\
Moderate & 0.336 & 1.331 & 1.4 & $0.103-19.013$ & 0.8 \\
Moderate to severe & 1.723 & 1.011 & 5.6 & $0.773-40.595$ & 0.088 \\
Severe abnormal & 4.143 & 1.062 & 63 & $7.865-504.648$ & $\mathbf{0 . 0 0 0 1}$ \\
Constant & -1.946 & - & - & - & -
\end{tabular}

B, probability of a type II error or power of test (estimate); SE, standard error; OR, odds ratio; $\mathrm{Cl}$, confidence interval; a-EEG, amplitude-integrated electroencephalography.

Boldface indicates a statistically significant difference with $P<0.05$.

prioritized over a-EEG and Sarnat score for predicting HIE.6)

The most accurate tool for assessing the severity of postnatal neurological damage in neonates with HIE is continuous 2channel EEG. ${ }^{17)}$ In the current study, the a-EEG analysis in infants with HIE showed that $31.3 \%, 11.8 \%, 17.6 \%$, and $39.2 \%$ of the neonates had normal, moderately abnormal, moderately to severely abnormal, and severely abnormal EEG, respectively. In terms of the EEG value, the background EEG pattern can predict neurological complications for term infants with HIE, whereas concomitance of EEG with clinical data such as GA, birth weight, brain imaging, and severity of HIE can provide a more accurate assessment of neurological complications. ${ }^{8,37)}$ Moreover, in infants with HIE who are treated with therapeutic hypothermia using a cool cap, severe abnormality in EEG is associated with brain tissue damage in MRI and predicts neurodevelopmental complications in these neonates. EEG abnormality has also a high positive predictive value for the selection of HIE newborns who can benefit from adjuvant therapies. ${ }^{38)}$

Srinivasakumar et al. ${ }^{20)}$ demonstrated therapeutic hypothermia was associated with a decrease in electroconvulsive seizures in neonates with moderate HIE, but not in those with severe HIE, which is similar to the results of our study. Gluckman et al. ${ }^{11)}$ reported that selective head cooling in neonatal encephalopathy improves survival without severe neurological disability in infants with less severe a-EEG changes. Nanavati et al. ${ }^{12)}$ also showed that EEG changes can be used as predictors of the outcome in infants with HIE.

In the present study, there were significant correlations between the severity of HIE in neonates and the need for mechanical ventilation and $55 \%$ of newborns who underwent mechanical ventilation died. Atıc et al. ${ }^{39)}$ demonstrated $94 \%$ of HIE infants during the cooling process require mechanical ventilation and no differences were found between the 2 cooling methods. The involvement of other organs, including the lung, worsens the prognosis of neonatal HIE. For this reason, mechanical ventilation is an independent factor in neonatal mortality.

Head cooling for all patients in our study began less than 4 hours after birth to achieve the desired effect. However, our study has some limitations, some clinical data not reported in detail because it had a retrospective design. This does not include infants with mild HIE.

In conclusion, this study showed that all cases of neonatal death in our study were severe HIE (stage 3). Advanced neonatal resuscitation was an independent predictor of death and severely abnormal a-EEG was an independent predictive factor of asphyxia severity in infants with HIE. 


\section{Conflicts of interest}

No potential conflict of interest relevant to this article was reported.

See the commentary "Which factors predict outcomes of neonates with hypoxic-ischemic encephalopathy following therapeutic hypothermia?" via https://doi.org/10.3345/cep. 2020.01459 .

\section{References}

1. Gillam-Krakauer M, Gowen Jr CW. Birth asphyxia. 2020 Aug 30. In: StatPearls [Internet]. Treasure Island (FL): StatPearls Publishing; 2020.

2. Kurinczuk JJ, White-Koning M, Badawi N. Epidemiology of neonatal encephalopathy and hypoxic-ischaemic encephalopathy. Early Hum Dev 2010;86:329-38.

3. Groenendaal F, Casaer A, Dijkman KP, Gavilanes AW, de Haan TR, ter Horst $\mathrm{HJ}$, et al. Introduction of hypothermia for neonates with perinatal asphyxia in the Netherlands and Flanders. Neonatology 2013;104:15-21.

4. Jacobs SE, Berg M, Hunt R, Tarnow-Mordi WO, Inder TE, Davis PG. Cooling for newborns with hypoxic ischaemic encephalopathy. Cochrane Database Syst Rev 2013;2013:CD003311.

5. Higgins RD, Raju T, Edwards AD, Azzopardi DV, Bose CL, Clark RH, et al. Hypothermia and other treatment options for neonatal encephalopathy: an executive summary of the Eunice Kennedy Shriver NICHD workshop. J Pediatr 2011;159:851-8.e1.

6. Ahearne CE, Boylan GB, Murray DM. Short and long term prognosis in perinatal asphyxia: an update. World J Clin Pediatr 2016;5:67-74.

7. Massaro AN, Evangelou I, Brown J, Fatemi A, Vezina G, McCarter R, et al. Neonatal neurobehavior after therapeutic hypothermia for hypoxic ischemic encephalopathy. Early Hum Dev 2015;91:593-9.

8. De Wispelaere LA, Ouwehand S, Olsthoorn M, Govaert P, Smit LS, de Jonge RC, et al. Electroencephalography and brain magnetic resonance imaging in asphyxia comparing cooled and non-cooled infants. Eur J Paediatr Neurol 2019;23:181-90.

9. Song X, Liao JX. Early evaluation of brain injury by electroencephalogram in neonates with asphyxia. Zhongguo Dang Dai Er Ke Za Zhi 2008;10: 299-300.

10. Chiang MC, Lien R, Chu SM, Yang PH, Lin JJ, Hsu JF, et al. Serum lactate, brain magnetic resonance imaging and outcome of neonatal hypoxic ischemic encephalopathy after therapeutic hypothermia. Pediatr Neonatol 2016;57:35-40.

11. Gluckman PD, Wyatt JS, Azzopardi D, Ballard R, Edwards AD, Ferriero DM, et al. Selective head cooling with mild systemic hypothermia after neonatal encephalopathy: multicentre randomised trial. Lancet 2005; 365:663-70.

12. Nanavati T, Seemaladinne N, Regier M, Yossuck P, Pergami P. Can we predict functional outcome in neonates with hypoxic ischemic encephalopathy by the combination of neuroimaging and electroencephalography? Pediatr Neonatol 2015;56:307-16.

13. Merchant N, Azzopardi D. Early predictors of outcome in infants treated with hypothermia for hypoxic-ischaemic encephalopathy. Dev Med Child Neurol 2015;57 Suppl 3:8-16.

14. Çelik Y, Atıcı A, Gülaşı S, Makharoblıdze K, Eskandari G, Sungur MA, et al. The effects of selective head cooling versus whole-body cooling on some neural and inflammatory biomarkers: a randomized controlled pilot study. Ital J Pediatr 2015;41:79.

15. American Collge of Obstetricians and Gynecologists (ACOG). Neonatal encephalopathy and cerebral palsy: executive summary. Obstet Gynecol 2004;103:780-1.

16. Levene MI, de Vries L. Hypoxic-ischemic encephalopathy. In: Martin RJ, Fanaroff AA, Walsh MC. Fanaroff and Martin's neonatal-perinatal medicine: disease of the fetus and infant. 8th ed. Philadelphia (PA): Elsevier,
2006:938-55.

17. Azzopardi DV, Strohm B, Edwards AD, Dyet L, Halliday HL, Juszczak E, et al. Moderate hypothermia to treat perinatal asphyxial encephalopathy. NEngl J Med 2009;361:1349-58.

18. al Naqeeb N, Edwards AD, Cowan FM, Azzopardi D. Assessment of neonatal encephalopathy by amplitude-integrated electroencephalography. Pediatrics 1999;103(6 Pt 1):1263-71.

19. Shankaran S, Laptook AR, Ehrenkranz RA, Tyson JE, McDonald SA, Donovan EF, et al. Whole-body hypothermia for neonates with hypoxicischemic encephalopathy. NEngl J Med 2005;353:1574-84.

20. Srinivasakumar P, Zempel J, Wallendorf M, Lawrence R, Inder T, Mathur A. Therapeutic hypothermia in neonatal hypoxic ischemic encephalopathy: electrographic seizures and magnetic resonance imaging evidence of injury. J Pediatr 2013;163:465-70.

21. Preeti S, Kadam A, Kadam S, Vaidya U, Kumar P, Bhagat I, et al. Anthropometric measures as biomarkers of neurodevelopmental outcomes of newborns with moderate to severe hypoxic ischemic encephalopathy. J Neonatal Perinatal Med 2019;12:127-34.

22. Pálsdóttir K, Thórkelsson T, Hardardóttir H, Dagbjartsson A. Fósturköfnun og heilakvilli-áhaettuthaettir og afleidingar fyrir nýbura Birth asphyxia, neonatal risk factors for hypoxic ischemic encephalopathy. Laeknabladid 2007;93:669-73.

23. Helsmoortel A, Schmitt E, Hascoët JM, Jellimann JM, Hamon I. Hypothermie thérapeutique contrôlée pour asphyxie périnatale: intérêt de l'électroencéphalogramme d'amplitude pour évaluer lindication Neonatal therapeutic hypothermia: amplitude-integrated electroencephalography to confirm the indication. Arch Pediatr 2013;20:181-5.

24. Shah GS, Singh R, Das BK. Outcome of newborns with birth asphyxia. JNMA J Nepal Med Assoc 2005;44:44-6.

25. Chen ZL, Liu J. Interpretation of the Experts' Consensus on the criteria for the diagnosis and grading of neonatal asphyxia in China. Transl Pediatr 2013;2:59-63.

26. Saade GR, Tita A. 289: Using venous cord gases to predict arterial cord gases and neonatal hypoxic ischemic encephalopathy. Am J Obstet Gynecol 2018;218(Suppl 1):S183.

27. Chen ZL, He RZ, Peng Q, Guo KY, Zhang YQ, Yuan HH. Clinical study on improving the diagnostic criteria for neonatal asphyxia. Zhonghua Er Ke ZaZhi 2006;44:167-72.

28. Collaborative Study Group of Neonatal Umbilical Cord Blood Gas Parameters. Multicenter clinical study on umbilical cord arterial blood gas parameters for diagnosis of neonatal asphyxia. Zhonghua Er Ke Za Zhi 2010;48:668-73.

29. Williams KP, Singh A. Umbilical artery blood gas parameters in neonates with early onset seizures who die. BJOG 2004;111:1042-5.

30. Afjeh SA, Sabzehei MK, Esmaili F. Neonatal resuscitation in the delivery room from a tertiary level hospital: risk factors and outcome. Iran J Pediatr 2013;23:675-80.

31. Duran R, Aladağ N, Vatansever U, Süt N, Acunaş B. The impact of Neonatal Resuscitation Program courses on mortality and morbidity of newborn infants with perinatal asphyxia. Brain Dev 2008;30:43-6.

32. Ramji S, Rasaily R, Mishra PK, Narang A, Jayam S, Kapoor AN, et al. Resuscitation of asphyxiated newborns with room air or $100 \%$ oxygen at birth: a multicentric clinical trial. Indian Pediatr 2003;40:510-7.

33. Ho NK. Decision-making: initiation and withdrawing life support in the asphyxiated infants in developing countries. Singapore Med J 2001;42: 402-5.

34. White CR, Doherty DA, Henderson JJ, Kohan R, Newnham JP, Pennell CE. Accurate prediction of hypoxic-ischaemic encephalopathy at delivery: a cohort study. J Matern Fetal Neonatal Med 2012;25:1653-9.

35. Beken S, Aydın B, Dilli D, Erol S, Zenciroğlu A, Okumuş N. Can biochemical markers predict the severity of hypoxic-ischemic encephalopathy? Turk J Pediatr 2014;56:62-8.

36. Mehta A, Chawla D, Kaur J, Mahajan V, Guglani V. Salivary lactate dehy. drogenase levels can provide early diagnosis of hypoxic-ischaemic encephalopathy in neonates with birth asphyxia. Acta Paediatr 2015;104: e236-40.

37. Chen Y, Wang ZP, Zhang ZF, Shen ZY. Prognostic value of electroencepha- 
lographic background patterns in full-term neonates with asphyxia. Zhongguo Dang Dai Er Ke Za Zhi 2007;9:425-8.

38. Dunne JM, Wertheim D, Clarke P, Kapellou O, Chisholm P, Boardman $\mathrm{JP}$, et al. Automated electroencephalographic discontinuity in cooled new. borns predicts cerebral MRI and neurodevelopmental outcome. Arch Dis Child Fetal Neonatal Ed 2017;102:F58-64.

39. Atıcı A, Çelik Y, Gülaşı S, Turhan AH, Okuyaz Ç, Sungur MA. Comparison of selective head cooling therapy and whole body cooling therapy in new. borns with hypoxic ischemic encephalopathy: short term results. Turk Pediatri Ars 2015;50:27-36.
How to cite this article: Basiri B, Sabzehei M, Sabahi M. Predictive factors of death in neonates with hypoxic-ischemic encephalopathy receiving selective head cooling. Clin Exp Pediatr 2021;64:180-7. https://doi.org/10.3345/cep.2019. 01382 